Review

\title{
Management of familial hypercholesterolemia in children and young adults: Consensus paper developed by a panel of lipidologists, cardiologists, paediatricians, nutritionists, gastroenterologists, general practitioners and a patient organization
}

\author{
O.S. Descamps ${ }^{\mathrm{a}, *, 1}$, S. Tenoutasse ${ }^{\mathrm{b}, 2}$, X. Stephenne ${ }^{\mathrm{c}, 3}$, I. Gies $^{\mathrm{d}, 2}$, V. Beauloye $^{\mathrm{e}, 2}$, M.-C. Lebrethon ${ }^{\mathrm{f}, 2}$, \\ C. De Beaufort ${ }^{\mathrm{g}, 2}$, K. De Waele ${ }^{\mathrm{h}, 2}$, A. Scheen ${ }^{\mathrm{i}, 1}$, E. Rietzschel ${ }^{\mathrm{j}, 1,4}$, A. Mangano $^{\mathrm{k}, 5}$, J.P. Panier ${ }^{\mathrm{k}, 5}$, \\ J. Ducobu ${ }^{1,1}$, M. Langlois ${ }^{\mathrm{m}, 1,6}$, J.-L. Balligand ${ }^{\mathrm{n}, 1,4}$, P. Legat ${ }^{\mathrm{o}, 7}$, V. Blaton ${ }^{1,1,6}$, E. Muls ${ }^{\mathrm{p}, 1}$, L. Van Gaal ${ }^{\mathrm{q}, 1}$, \\ E. Sokal ${ }^{\mathrm{c}, 3}$, R. Rooman ${ }^{\mathrm{r}, 2}$, Y. Carpentier ${ }^{\mathrm{s}, 1,8}$, G. De Backer $^{\mathrm{j}, 1,4}$, F.R. Heller $^{\mathrm{a}, 1}$
}

a Département de Médecine Interne et Centre de Recherche Médicale de Jolimont, Hôpital de Jolimont, Haine Saint-Paul, Belgium

${ }^{\mathrm{b}}$ Endocrinologie pédiatrique, Hôpital Universitaire Des Enfants, Bruxelles, Belgium

c Unité de gastroentérologie pédiatrique, Cliniques Universitaires Saint-Luc, Bruxelles, Belgium

d Department of Pediatrics, UZ Brussel, Vrije Universiteit Brussel, Belgium

endocrinologie pédiatrique, Cliniques universitaires Saint-Luc, Bruxelles, Belgium

${ }^{\mathrm{f}}$ C.H.U de Liège-site N.D des Bruyères, Chênée, Belgium

g Clinique Pédiatrique/CH de Luxembourg, GD de Luxembourg, Belgium

h Department of Pediatry, Ghent University Hospital, Ghent, Belgium

${ }^{i}$ Division of Diabetes, Nutrition and Metabolic Disorders, CHU Sart Tilman, University of Liege, Belgium

j Department of Cardiovascular Disease, Ghent University Hospital, Ghent, Belgium

${ }^{\mathrm{k}}$ Belgian Patient Association for Familial Hypercholesterolemia, Belgium

${ }^{1}$ Université de Mons, Belgium

m Department of Laboratory Medicine, AZ St-Jan Bruges, Belgium

n Département de Médecine Interne. Cliniques universitaires Saint-Luc, Bruxelles, Belgium

- Société Scientifique de Médecine Générale, PromoSanté \& Médecine Générale asbl, Bruxelles, Belgium

p Department of Endocrinology-Nutrition, University Hospital Gasthuisberg, Leuven, Belgium

${ }^{q}$ Department of Endocrinology, Diabetology and Clinical Pharmacology, Antwerp University Hospital, Belgium

${ }^{\mathrm{r}}$ Department of Pediatric Endocrinology-Diabetology, Antwerp University Hospital, Belgium

${ }^{s}$ Laboratory of Experimental Surgery, Université Libre de Bruxelles, Belgium

\section{A R T I C L E I N F O}

\section{Article history:}

Received 30 October 2010

Received in revised form 8 June 2011

Accepted 9 June 2011

Available online 17 June 2011

\section{Keywords:}

Familial hypercholesterolemia

Children

Cardiovascular disease

Cholesterol

Treatment consensus paper

\begin{abstract}
A B S T R A C T
Since heterozygous familial hypercholesterolemia ( $\mathrm{HeFH})$ is a disease that exposes the individual from birth onwards to severe hypercholesterolemia with the development of early cardiovascular disease, a clear consensus on the management of this disease in young patients is necessary. In Belgium, a panel of paediatricians, specialists in (adult) lipid management, general practitioners and representatives of the FH patient organization agreed on the following common recommendations.

1. Screening for HeFH should be performed only in children older than 2 years when HeFH has been identified or is suspected (based on a genetic test or clinical criteria) in one parent.

2. The diagnostic procedure includes, as a first step, the establishment of a clear diagnosis of HeFH in one of the parents. If this precondition is satisfied, a low-density-lipoprotein cholesterol (LDL-C) level above $3.5 \mathrm{mmol} / \mathrm{L}(135 \mathrm{mg} / \mathrm{dL})$ in the suspected child is predictive for differentiating affected from non-affected children.
\end{abstract}

\footnotetext{
* Corresponding author. Tel.: +32 (0) 64 233167; fax: +32 (0) 64233677.

1 Belgian Lipid Club.

2 Belgian Study Group of Paediatric Endocrinology (BSGPE) and Belgian Society of Pediatry.

3 Belgian Society Pediatric Hepatology, Gastroenterology and Nutrition (Besphgan).

4 Belgian Society of Cardiology.

5 Belgian Patient Association for FH.

6 Belgian Society of Clinical Chemistry.

7 Société Scientifique de Médecine Générale, PromoSanté \& Médecine Générale asbl.

8 Belgian Society of Nutrition.
} 
LDL-receptor gene

Apolipoprotein B

Statins

Ezetimibe

Fibrates

Plant sterols

Stanols

Diagnostic criteria
3. A low saturated fat and low cholesterol diet should be started after 2 years, under the supervision of a dietician or nutritionist.

4. The pharmacological treatment, using statins as first line drugs, should usually be started after 10 years if LDL-C levels remain above $5 \mathrm{mmol} / \mathrm{L}(190 \mathrm{mg} / \mathrm{dL})$, or above $4 \mathrm{mmol} / \mathrm{L}(160 \mathrm{mg} / \mathrm{dL})$ in the presence of a causative mutation, a family history of early cardiovascular disease or severe risk factors. The objective is to reduce LDL-C by at least $30 \%$ between 10 and 14 years and, thereafter, to reach LDL-C levels of less than $3.4 \mathrm{mmol} / \mathrm{L}(130 \mathrm{mg} / \mathrm{dL})$

Conclusion: The aim of this consensus statement is to achieve more consistent management in the identification and treatment of children with HeFH in Belgium.

(C) 2011 Elsevier Ireland Ltd. All rights reserved.

\section{Contents}

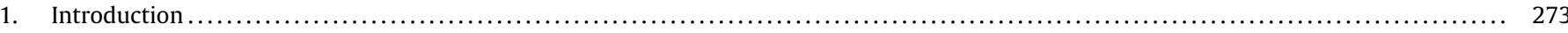

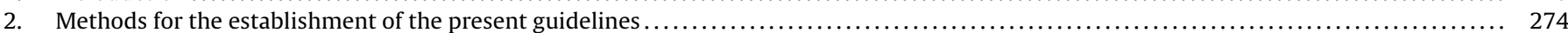

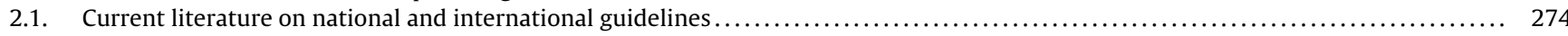

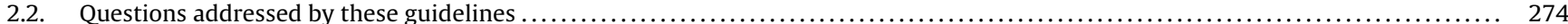

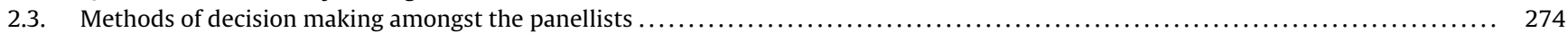

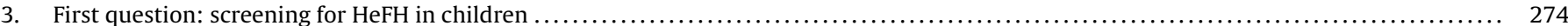

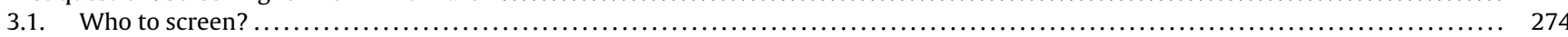

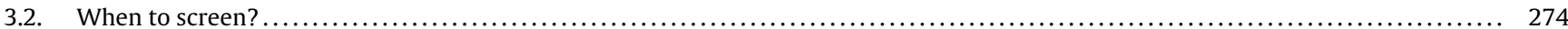

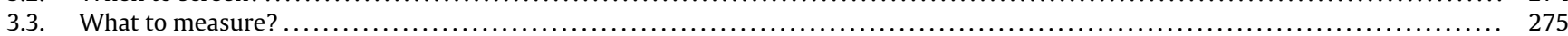

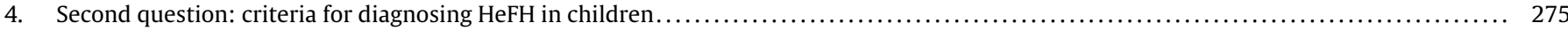

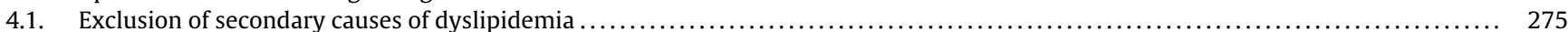

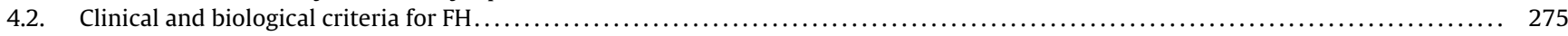

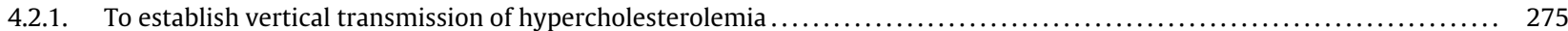

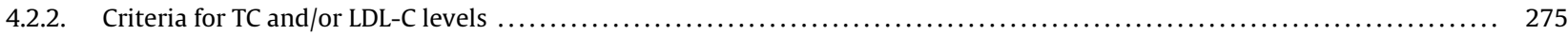

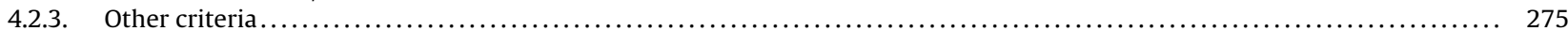

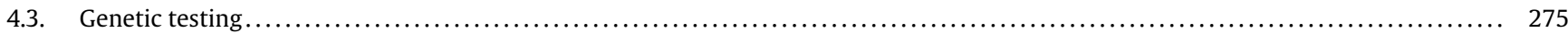

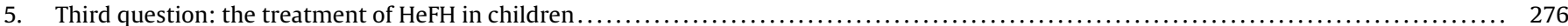

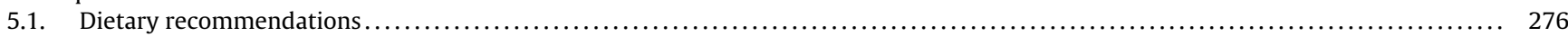

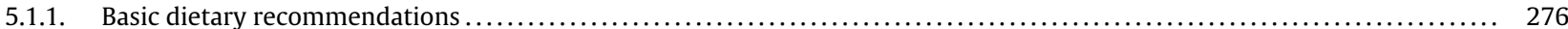

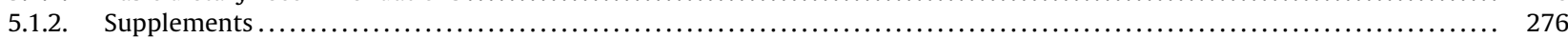

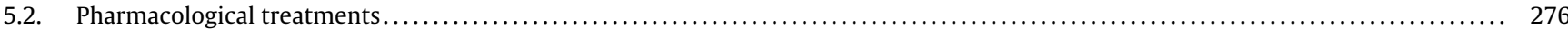

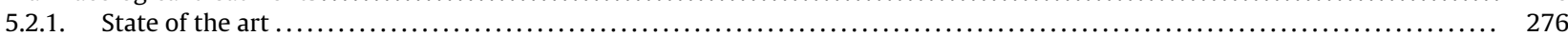

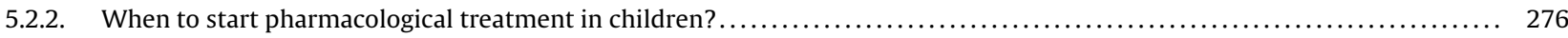

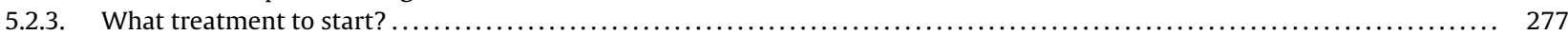

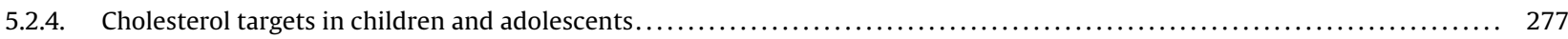

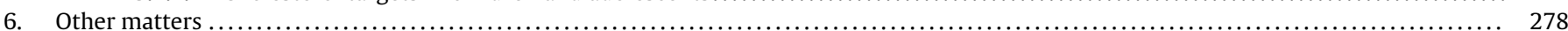

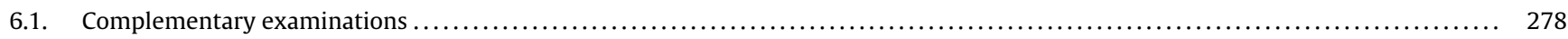

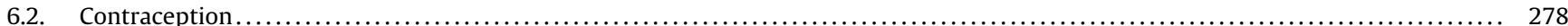

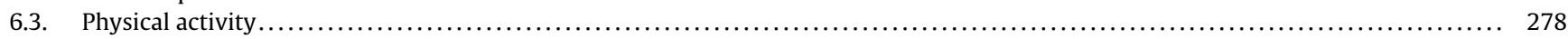

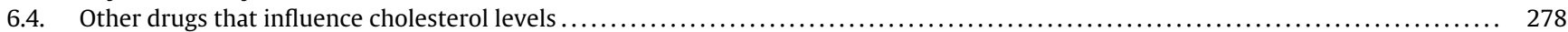

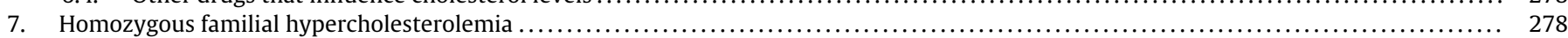

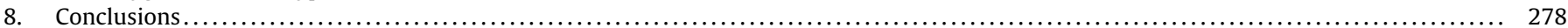

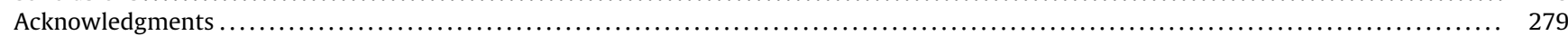

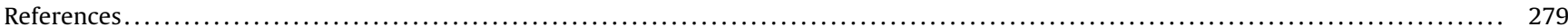

\section{Introduction}

In patients with heterozygous familial hypercholesterolemia $(\mathrm{HeFH})$, hypercholesterolemia is already present at birth [1] and results in early atherosclerotic lesions, which can be detected by carotid intima media thickness (IMT) measurement as early as 10 years of age [1]. It is reasonable to question when to identify individuals at risk and when to start treatment of HeFH. These questions are not easily answered because there is little evidence to support any particular course of action (or even lack of action). Recently, however, intervention studies in children have provided scientific arguments in favour of treating FH children [2,3]. Firstly, high cholesterol in children has a substantial subclinical impact, which is already measurable from the age of 5 years. In children with a mutation, endothelial dysfunction can be observed (measured by the dilatation of the brachial artery associated with an intense post-ischaemic flow of arterial blood) [4], as well as a greater IMT thickening detected by carotid echography [5-7]. Secondly, high cholesterol levels in childhood increasingly appear to be a good predictor of cardiovascular risk later in life [8,9]. Thirdly, some interventional studies with statins in children were well tolerated at least in the short-term $[10,11]$. The statins were highly efficacious at reducing low-density-lipoprotein cholesterol (LDL-C) by -30 to $-40 \%$ in studies up to 2 years, and, above all, the development/progression of atherosclerosis measured by endothelial function [12] or IMT $[13,14]$. It should be noted that the Food and Drugs Administration (FDA) approved treatment with simvastatin in 1995, atorvastatin $10-20 \mathrm{mg}$ in 2000 and pravastatin in 2002 for children aged 10 years or more.

While the benefits, objectives and treatment of HeFH are well defined in adults [15], a clear consensus does not exist for the management of children with HeFH. There is, nevertheless, an urgent need for a consensus between paediatricians, general practitioners and specialists in internal medicine, as the HeFH patient will 
besuccessively confronted with these specialities in the course of his/her life. Consistent recommendations are pivotal to ensure compliance with the long-term treatment of these patients. The rationale to develop HeFH guidelines is obvious. Firstly, $\mathrm{HeFH}$ is a clearly defined condition where elevated levels of cholesterol in young people persist into adulthood. This is not always the case with other causes of hypercholesterolemia, especially those associated with polygenic disorders, where the elevated levels of cholesterol depend to a greater extent on gene-environmental interaction, and thus, where cholesterol levels vary with the exposure of the patients to a variable environment (food intake, physical activity, etc.). Secondly, HeFH is a dominantly inherited disease, resulting in the transmission of the disease to $50 \%$ of the offspring of the parent with HeFH. Thirdly, HeFH may be clearly defined by genetic testing in both the parent and the child. Finally the hypercholesterolemia associated with $\mathrm{HeFH}$ is clearly considered as a high risk condition for cardiovascular disease (CVD), even higher than the risk of non-FH-hypercholesterolemia at similar LDL-C levels [16].

The objective of this consensus is to propose recommendations for the diagnosis and treatment, and to define the objectives to be attained in the management, of children and adolescents presenting with $\mathrm{FH}$, taking into account recently available data.

\section{Methods for the establishment of the present guidelines}

A first panel (DOS, TS, SX, GI, BV, LMC, DBC, DWK) collected all the papers related to this subject using a MEDLINE search focusing first on reviews and current national and international guidelines, after having agreed the methodology and clearly defining the questions to be answered. This first panel wrote the first draft of the consensus, which was then distributed amongst a comprehensive panel of national experts (the other co-authors).

\subsection{Current literature on national and international guidelines}

There are many reviews and opinions on clinical management of FH (see most recently: [3,17]), but very few national guidelines developed by consensus. National guidelines exist in the United States [18] and more recently in the UK [19]. There are also some position papers from experts in Spain [15] and in The Netherlands [20]. There are currently no international guidelines.

\subsection{Questions addressed by these guidelines}

In children, the questions to be resolved are: (a) When should we search for HeFH in children and how? (b) When should we suspect HeFH and how can we confirm the diagnosis? (c) When should we start treatment, what type of treatment should be used and which target level of LDL-C should be recommended? Furthermore, we discuss other important practical issues, such as oral contraception in FH girls, physical activity and use of certain medications that potentially affect cholesterol levels.

\subsection{Methods of decision making amongst the panellists}

All panellists read the various published guidelines and opinion papers. We also performed a careful analysis of some specific questions by delegating 2 or 3 panellists to study these questions. For each question, alternatives and arguments FOR and AGAINST each alternative were established. The best alternative for each question was decided by voting according to the AGREE (Appraisal of Guidelines Research \& Evaluation) protocol [21], which is commonly used to develop clinical practice guidelines.
Table 1

Recommendations on screening and diagnosis.

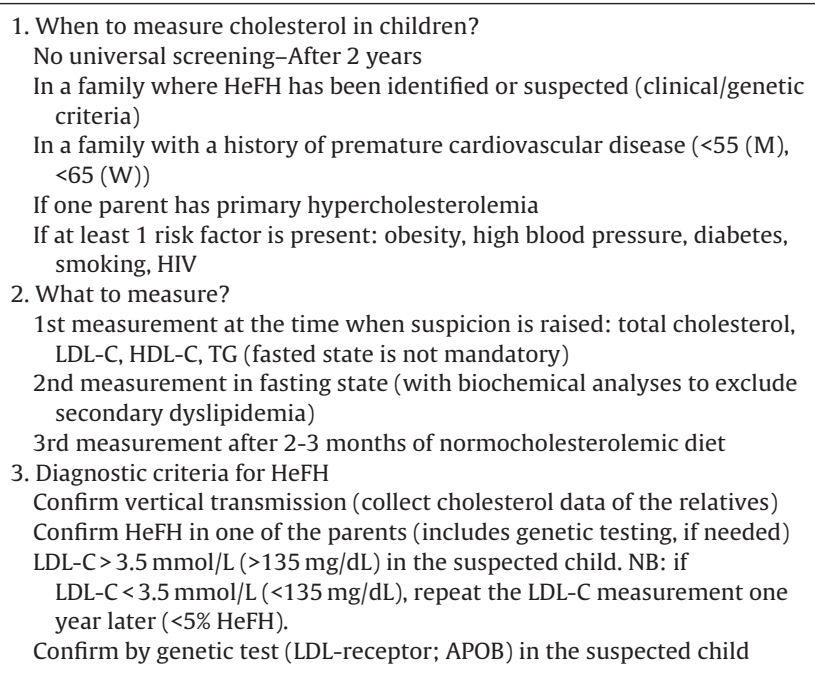

\section{First question: screening for HeFH in children}

\subsection{Who to screen?}

There are three situations (Table 1 ) where children can be suspected of $\mathrm{FH}$ (with probability decreasing from a to $\mathrm{c}$ ): (a) a child from a family where HeFH has been identified or suspected (clinical/genetic criteria), (b) a child from a family with a history of premature (before age 55 years in men and 65 years in women) CVD or (c) a child from parents of whom one or both displayed primary hypercholesterolemia. This emphasises the importance of assessing, in all children visiting a doctor (whatever the reason), the family history regarding cholesterol levels, CVD and confirmed or suspected genetic conditions.

The last situation in Table 1 (presence of at least 1 risk factor: obesity, high blood pressure, diabetes, smoking, HIV, etc.) is not strictly related to the search for $\mathrm{HeFH}$, but is given as a matter of completeness for cholesterol screening in general. We must keep in mind that screening for $\mathrm{FH}$ is part of the effort to identify children at high cardiovascular risk, whatever the cause of this high risk. These causes include not only genetic dyslipidemia, but also the presence of risk factors, such as hypertension, obesity, metabolic syndrome and active or passive smoking, as well as diseases associated with cardiovascular complications such as diabetes, HIV infection, systemic lupus erythematosus, kawasaki's disease, organ transplantation or being a survivor of childhood cancer. We refer to some of the specific guidelines regarding these situations [22-24].

National screening for cholesterol values at birth or later is currently not recommended [26]. Although such universal screening is technically feasible in the context of neonatal screening on filtered paper or later during the school years, it may be expensive (especially if the option of genetic analyses is chosen), requires solving a number of ethical issues and needs governmental decision and support.

\subsection{When to screen?}

The panellists agree that selective screening should be recommended after the age of 2 years. There are three reasons. Firstly, plasma cholesterol levels are lowest at birth [25] and increase rapidly in the first weeks of life, and then gradually until 2 years of age, when lipid levels become quite constant up to the adolescent growth spurt and are almost similar to those seen in young 
adults [26]. Secondly, dietary treatment is not recommended in the literature before the age of 2 years [26] (although one recent paper reported the safety of early dietary changes, as early as from 12 months onwards [27]). And finally, the younger the children are, the less chance of overlap between LDL-C levels in subjects with $\mathrm{HeFH}$ and without HeFH. As with the UK NICE guidelines [19], we recommend screening before the age of 10 years. Indeed, after this age, dietary habits will be more difficult to correct and there is a large variation in LDL-C (with an average 10-20\% fall) during adolescence [28] with increasing risk of false negative results.

\subsection{What to measure?}

We agree that the first diagnostic procedure for $\mathrm{FH}$ screening is the measurement of LDL-C levels. Still, we recommend that a classic lipid profile including total cholesterol (TC), triglycerides (TG), LDL-C and high-density-lipoprotein cholesterol (HDL-C) should be drawn as soon as there is any suspicion of HeFH. Also, to avoid any delay with the risk of loss to follow up, we propose to perform the venepuncture or capillary blood sampling if near-patient testing is being recommended at the moment of the visit, even if the subject is in a non-fasting state (TG is the only parameter really affected by a meal and this is not critical for the diagnosis of HeFH). LDL-C should be determined as per current practice by calculation according to the Friedewald equation "LDL-C $=\mathrm{TC}-(\mathrm{HDL}-\mathrm{C}+\mathrm{TG} / 2.2)$ " (all concentrations in $\mathrm{mmol} / \mathrm{L}$ ). If $\mathrm{TG}>4.5 \mathrm{mmol} / \mathrm{L}$ (or $400 \mathrm{mg} / \mathrm{dL}$; an exceptional scenario in $\mathrm{HeFH}$, unless there is an additional medical condition such as diabetes) this formula cannot be used and direct LDL-C should be measured.

If cholesterol is high (see cut-off values below), we propose a second lipid profile be performed, in a fasting state, along with biochemical analyses to rule out secondary dyslipidemia (including: hepatic enzymes, renal function, thyroid hormones, glycaemia, and albuminuria/proteinuria) and for other risk factors (e.g. lipoprotein(a) which is often elevated in HeFH [1]). In the absence of secondary causes, a third measurement will be important after 2 or 3 months of diet, especially for patients with poor nutritional habits. At this stage, it is reasonable to refer the patients to a specialised centre.

\section{Second question: criteria for diagnosing HeFH in children}

\subsection{Exclusion of secondary causes of dyslipidemia}

When primary hyperlipidemia has been confirmed, the first steps are correction of dietary habits and exclusion of secondary causes of hyperlipidemia. It is important to keep in mind other possible causes mimicking HeFH (pure elevated cholesterol, possibly associated with hypertriglyceridemia), although most are very rare (Table 2).

\subsection{Clinical and biological criteria for $F H$}

Once primary hyperlipidemia has been confirmed, the likelihood of the genetic nature of hypercholesterolemia should be checked on the basis of the existence of vertical transmission of hypercholesterolemia and of LDL-C levels.

\subsubsection{To establish vertical transmission of hypercholesterolemia}

We strongly advocate that it is important to have, or to establish, first a clear diagnosis of HeFH in one of the parents before trying to confirm the diagnosis in the child. The confirmation of HeFH in one parent is needed, since (a) vertical transmission is an important criterion for diagnosing FH in the child, (b) the parent is at greater risk than the child, and (c) the parents' understanding of the genetic
Table 2

Secondary causes of hypercholesterolemia mimicking FH in children.

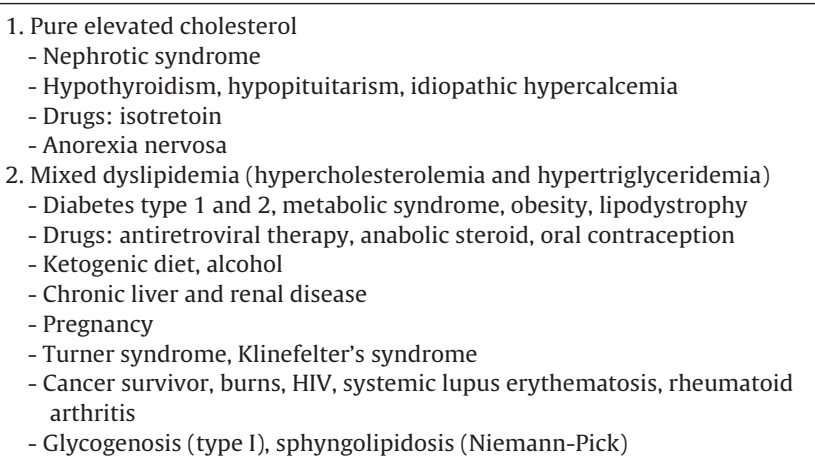

nature of the hypercholesterolemia of their child may improve the compliance to treatment of both the parent and the child.

When such certainty is not possible (only a clinical suspicion in the parent or absent parent), the establishment of the vertical transmission of hypercholesterolemia requires the collection of cholesterol levels (or in its absence, cardiovascular data) from as many family members as possible. When available, it is helpful to plot the cholesterol levels to demonstrate the bimodal distribution of these levels in the family, which is typical of a dominantly inherited genetic disease. This procedure is often restricted by the fact that most families are too small.

\subsubsection{Criteria for $T C$ and/or $L D L-C$ levels}

The majority of children with HeFH have TC levels above $6.5 \mathrm{mmol} / \mathrm{L}(250 \mathrm{mg} / \mathrm{dL})$ with levels of LDL-C in excess of $5.5 \mathrm{mmol} / \mathrm{L}$ ( $200 \mathrm{mg} / \mathrm{dL})$. Sometimes LDL-C levels below $4 \mathrm{mmol} / \mathrm{L}(160 \mathrm{mg} / \mathrm{dL})$ are encountered in children who carry mutations on the LDL receptor or apolipoprotein B (ApoB) genes. In The Netherlands, Wiegman and colleagues [29], after studying 1034 children from families with $\mathrm{FH}$ (confirmed by genetic testing), noted that a fasting LDL-C level of $3.5 \mathrm{mmol} / \mathrm{L}(135 \mathrm{mg} / \mathrm{dL})$ predicted the presence of $\mathrm{FH}$ with a posttest probability of 0.98 for differentiating affected children from non-affected children. As in most epidemiological studies of Belgian children, the levels of TC (LDL-C was not measured in these studies) were quite similar to those of Wiegman et al. in the Dutch non-FH children. We therefore decided to use the same cut-off criteria for LDL-C.

\subsubsection{Other criteria}

We should not expect to find tendon xanthomas and corneal arcus in young subjects with $\mathrm{HeFH}$, as this pathognomonic clinical sign generally appears later in life [1]. However, if present, these signs do suggest the possibility of homozygous FH (see [8]).

\subsection{Genetic testing}

If a mutation has been identified in the parent, the demonstration of the same mutation in the child is unambiguous proof of the diagnosis of HeFH. Only the genetic demonstration of a functional mutation in the genes for the LDL receptor, PCSK9 or ApoB provides an unequivocal diagnosis, which is advisable when lifelong drug treatment is being considered. This testing needs to be carried out only once in a lifetime. As different mutations produce only small differences in LDL-C levels compared to the large variability in LDL$C$ levels observed in different families, there is no clear evidence of any correlation between specific mutations and the severity of the disease or to suggest any utility in taking into account the type of mutation to make decisions regarding therapeutic strategy. 
Listed below are some other recommendations regarding this testing:

- Refer the child to a specialist for carrying out the testing. There is however no need to visit a genetic centre to have the genetic test. FH treatment consists of drugs that, except for their unusually high dosage and frequent use in combination, are commonly used in the general population. HeFH may occasionally require psychological support and family counselling. HeFH patients require follow up by a specialist well aware of the management of this disease, at least partially with the collaboration of their general practitioner.

- Clarify the diagnosis of HeFH in one of the parents first. Therefore, if possible and not yet done, it is necessary to perform the genetic test first in the hypercholesterolemic parent (or the closest relative).

- In children of parents with a FH mutation, genetic testing should only be performed in children with LDL-C levels suggesting possible HeFH (see clinical diagnosis). In other children of the same family with lower cholesterol levels, follow up is required and a genetic test should be performed as soon as their LDL-C levels reach the possible HeFH threshold.

- In children of parents without a positive genetic test: as the genetic test is not $100 \%$ sensitive [2], not finding a mutation in the parent does not mean that the child does not have HeFH. Even in the absence of a positive genetic test, a clinical diagnosis of $\mathrm{HeFH}$ can be considered with some certainty if the level of LDL-C is above the 95 th percentile $(3.5 \mathrm{mmol} / \mathrm{L}$ or $135 \mathrm{mg} / \mathrm{dL})$ [30] and if the family has a history of early CVD and/or tendon xanthoma.

\section{Third question: the treatment of HeFH in children}

\subsection{Dietary recommendations}

\subsubsection{Basic dietary recommendations}

A restricted fat and cholesterol diet is mandatory. This diet should restricted fat intake to $28 \%$ and includes $<8 \%$ saturated fat and $<75 \mathrm{mg} / 1000 \mathrm{kcal}$ cholesterol [31]. Furthermore, a hypocaloric diet is recommended in case of excess weight. These recommendations can be implemented after 2 years of age, under the supervision of a dietician or nutritionist. The composition of fatty acids and cholesterol is an important aspect of the dietary recommendations made to the parents and the young HeFH patient [32]. Saturated fatty acids (SFAs), and above all palmitic acid, the most common SFA, present in dairy products, reduce the expression of the LDL receptor and increase the synthesis of VLDL (very-low-density lipoprotein). In contrast, unsaturated fatty acids, such as linoleic and oleic acid, reduce LDL-C when they replace SFAs (oleic acid being a better choice as linoleic acid reduces HDL-C). Reducing saturated fats and cholesterol in the diet of children does not alter their nutritional status, growth, or pubertal development [33].

\subsubsection{Supplements}

To date, all studies of supplements are small in size and have short follow up periods. The most studied supplements are phytosterol esters and stanol esters. These supplements inhibit the intestinal absorption of cholesterol, even in the presence of a diet poor in cholesterol, and reduce LDL-C by $10-15 \%$ in children with FH. However, sterols do not improve flow mediated dilatation [34], they accumulate in atheroma [35] and reduce the level of some fat-soluble vitamins [36]. Therefore, we currently do not recommend the use of sterol- and stanol-enriched foods or supplements in young children.

Supplements containing fatty acid $n-3$ poly-unsaturates (alphalinolenic acid [ALA] of plant origin, eicosapentaenoic acid [EPA] and docosahexaenoic acid [DHA] found in oily fish) are known to have a positive effect on cardiovascular health in adults post myocardial infarction, but there is a lack of clear evidence in primary prevention [37]. Two studies with fatty acid $n-3$ polyunsaturates in children demonstrated slight increases in cholesterol levels (mainly the HDL fractions) and beneficial effects on flow mediated dilation [38]. We do not recommend supplementation with omega-3 capsules in children. However, the basic diet must include poly-unsaturated fatty acids, preferably by increasing consumption of fish.

Another potentially interesting supplement is soy protein. One meta-analysis showed that consumption of soy protein, containing isoflavones, was associated with a $3 \%$ reduction of LDL-C, a $1.5 \%$ increase of HDL-C and a 5\% reduction of triglycerides [39]. It is still unclear whether the cholesterol lowering effect is due to the soy protein or the isoflavones. A recent study in children using a dose of $0.25-0.5 \mathrm{~g} / \mathrm{kg} /$ day of soy protein showed promising results with an LDL-C/TC decrease of $6.4 \% / 7.7 \%$ [40], but more data are needed before we can systematically recommend the medicinal use of soy protein in children. In rare cases, soy protein intake can also cause gynecomastia [41].

Other supplements mentioned in the literature are cereals, grape pips, tea, linseed, psyllium, guar gum, garlic, dried fruits, etc., but these have not been the subject of randomised studies in children and are therefore not recommended.

\subsection{Pharmacological treatments}

\subsubsection{State of the art}

Intervention studies with statins in children were shown to be well tolerated (no side effects, no growth problems, no muscle or liver toxicity) [11] and efficacious at reducing LDL-C ( -30 to $-40 \%$ for study lengths of 2 years). Statins have demonstrated efficacy at improving the clinical outcome in adults [42] but there have been no long-term outcome studies in children. However, shortterm studies have demonstrated improvement in coronary heart disease surrogate endpoints for atherosclerosis in children, such as improvement in endothelial function after 28 weeks' treatment [12] and a change in IMT after 2 years' treatment [13,14].

\subsubsection{When to start pharmacological treatment in children?}

The panellists suggest considering pharmacological treatment routinely in children over the age of 10 years and after 6-12 months of dietary treatment (restricted fat and cholesterol), in the conditions summarised in Table 3. Early treatment is mainly motivated by the fact that starting a treatment before puberty will ensure better control by the parents and better acceptance by the child. It was decided that drug therapy needed to be restricted to those for whom we have the strongest confirmation of HeFH (e.g. those carrying a clear causative mutation). Since the presence of LDLC $>5 \mathrm{mmol} / \mathrm{L}(190 \mathrm{mg} / \mathrm{dL})$ and of familial premature CVD (in the presence of LDL-C above $4 \mathrm{mmol} / \mathrm{L}$ [160 mg/dL]) are both not only indicative of $\mathrm{HeFH}$ but also of greater CVD risk. It is therefore reasonable to start drug therapy early in this condition.

Other risk factors may also lead to early prescribing of drug treatment, but this is left at the discretion of the prescriber, depending on the number and severity of risk factors. Such conditions are: diabetes, metabolic syndrome, hypertension, HIV infection, systemic lupus erythematosus, organ transplantation or survivor of childhood cancer. In the case of diabetes, and when a genetic test cannot confirm the genetic origin of the dyslipidemia, to decide whether a child has obesity-related hypercholesterolaemia or HeFH may be difficult. However, in both cases, if LDL-C is above $4 \mathrm{mmol} / \mathrm{L}$ (>160 $\mathrm{mg} / \mathrm{dL}$ ), we recommend starting treatment. This view is in line with the current recommendation of statin treatment in diabetic children [43]. Other less severe conditions which may be indicators for treatment, especially if they are present in 
Table 3

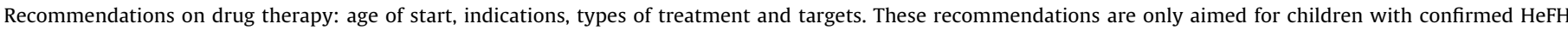

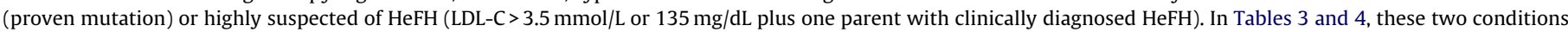
are aggregated under the term "HeFH children".

\begin{tabular}{|c|c|c|}
\hline Ages & Indications & Treatments \\
\hline$\leq 2$ years & All HeFH children & $\mathrm{R} /$ no active screening, no diet. \\
\hline$>2$ years & All HeFH children & R/lifestyle, diet, no smoking, physical activity \\
\hline $10-14$ years & $\begin{array}{l}\text { Only HeFH children with } \mathrm{LDL}-\mathrm{C}>4 \mathrm{mmol} / \mathrm{L} \\
\text { ( }>160 \mathrm{mg} / \mathrm{dL} \text { ) despite effort of diet and one of the } \\
\text { following conditions: } \\
\text { - a proven mutation } \\
\text { - or a familial premature CVD } \\
\text { - or } \mathrm{LDL}-\mathrm{C}>5 \mathrm{mmol} / \mathrm{L}(>190 \mathrm{mg} / \mathrm{dL}) \\
\text { - or presence of disease at risk of CVD } \\
\text { - or presence of several risk factors }{ }^{\mathrm{b}}\end{array}$ & $\begin{array}{l}\mathrm{R} / \text { prescribe statin to achieve a } \mathrm{LDL}-\mathrm{C} \text { reduction of at } \\
\text { least } 30 \% \text {. If intolerance to statin, ezetimibe } 10 \mathrm{mg} / \mathrm{D}\end{array}$ \\
\hline 14-18 years & Same indications as above & $\begin{array}{l}\mathrm{R} / \text { titrate dosage of statin, change to more potent statin } \\
\text { or add ezetimibe } 10 \mathrm{mg} / \mathrm{D} \text { (if intolerance to higher } \\
\text { statin dosage), to target } \mathrm{LDL}-\mathrm{C}<3.4 \mathrm{mmol} / \mathrm{L} \\
(<130 \mathrm{mg} / \mathrm{dL}) \text {. }\end{array}$ \\
\hline$>18$ years & All HeFH patients & $\begin{array}{l}\mathrm{R} / \text { titrate dosage of statin, change to more potent statin } \\
\text { or add ezetimibe (or nicotinic acid if high TG or low } \\
\text { HDL-C) to target LDL-C }<2.5 \mathrm{mmol} / \mathrm{L} \text { ( }<100 \mathrm{mg} / \mathrm{dL} \text { ). }\end{array}$ \\
\hline
\end{tabular}

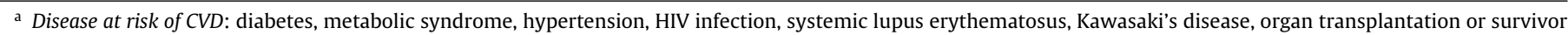
of childhood cancer.

b Risk factors: obesity, male sex, active or passive smoking, oral contraception in girls and emerging risk factors or markers such lipoprotein(a), homocysteine, hsCRP.

combination, are: obesity, male sex, active or passive smoking, oral contraception in girls and emerging risk factors or markers such as lipoprotein(a), homocysteine and hsCRP.

Some children with a mutation in the LDL receptor, who therefore have HeFH, have LDL-C levels below $4 \mathrm{mmol} / \mathrm{L}(160 \mathrm{mg} / \mathrm{dL})$. In these children, in the absence of other risk factors, it is not necessary to prescribe a pharmacological treatment before the age of 18 years.

\subsubsection{What treatment to start?}

5.2.3.1. Statins. For children who meet the criteria for starting pharmacological treatment, a statin is recommended as the first line treatment. In children, the efficacy and safety profile appears to be the same as in adults. The choice of statin may depend on local (regulatory) availability for use in children. For example, in Belgium, reimbursement modalities and indications for children (age $>10$ years) exist only for atorvastatin $10-80 \mathrm{mg} /$ day and rosuvastatin $10-20 \mathrm{mg} /$ day. However, this may change in the future.

5.2.3.1.1. Efficacy and safety. A recent systematic review and meta-analysis [44] has been conducted on clinical trials and observational studies (10 trials; $N=947$ individuals) to assess the evidence for efficacy and safety of statin therapy in children and adolescents (age range 8-18 years) with $\mathrm{HeFH}$, treated for a duration ranging from 6 to 96 weeks. The pooled reduction in LDL-C was $2 \mathrm{mmol} / \mathrm{L}(73 \mathrm{mg} / \mathrm{dL})$ compared to placebo $(p<0.0001)$, but efficacy varied according to the statin and dose used. In these trials, and other prospective case series, there were no significant adverse events. Amongst all statins, pravastatin has so far been the only drug studied for its effect on the surrogate endpoints of atherosclerosis [12-14]. It must be noted that while most clinical trials are of short duration, practical experience with statins now exceeds 20 years, without any report of long-term undesirable effects, and in particular, no reports of side effects on pubertal, intellectual or physical development.

5.2.3.1.2. Cautions. Monitoring creatine kinase levels is mandatory, but it is necessary to be aware that increases in enzymes in teenagers will most often be due to other causes, such as vigorous physical activity, especially contact sports, body building, athletics, football, etc. Serum creatine phosphokinase (CK) activity (muscle), alanine aminotransferase (ALAT) and aspartate aminotransaminase (ASAT) levels need to be measured before starting therapy and during follow up (1-3 months after starting, then yearly). The cut-off value that should lead to an interruption in treatment with the current lipid-lowering drug is five times the upper limit of normal for $\mathrm{CK}$ and three times the upper limit of normal for ALAT and ASAT, measured on two separate occasions. Thereafter, we propose to carefully reintroduce the current drug at a lower dosage or another drug (probably another statin) after 3 months of withdrawal. When none of the statins are well tolerated, prescription of ezetimibe can be proposed. Eventually, if LDL-C remains too high, bile acid sequestrants, colestyramine, colestipol or better tolerated, colesevelam may be prescribed in combination with the statin.

5.2.3.2. Others. Fibrates and derivatives of nicotinic acid are generally not used in children with HeFH. There is only one (pre-statin era) study published in 1985 [45] on the use of fibrates (bezafibrate) in HeFH children, which showed a $15 \%$ reduction of TC (LDL-C was not reported). Although ezetimibe is already registered for children aged over 10 years with $\mathrm{HeFH}$, it has not yet been studied in a suitable way in children with HeFH. There is at present no evidence on the benefit of ezetimibe on cardiovascular outcomes and there are some controversial results on the benefit on surrogate endpoints of atherosclerosis in adults [46]. There is however a retrospective review in HeFH children [47], which showed that addition of ezetimibe $(10 \mathrm{mg} /$ day) to treatment with atorvastatin or simvastatin achieved an additional LDL-C reduction. The incidence of side effects and the safety profile in co-administration were similar to those of patients receiving statins alone. We recommend that unless a statin is not tolerated, ezetimibe should not be considered before age 18 at the present time. Bile acid chelators like cholestyramine and colestipol which were studied [48] and considered in the past as first choice, are currently rarely used, because of a bad tolerance profile leading to very poor compliance, especially amongst adolescents. The recently marketed, colesevelam hydrochloride, is better tolerated in children [49].

\subsubsection{Cholesterol targets in children and adolescents}

In children, it is not appropriate to recommend a "therapeutic target" since no clinical studies have yet demonstrated the regression or the absence of progression of clinical parameters according to the level of LDL-C. In adults, there is clear evidence 
Table 4

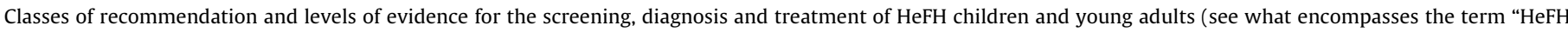
children" in the legend of Table3).

\begin{tabular}{|c|c|c|}
\hline Recommendations & Class of recommendation & Level of evidence \\
\hline Children of parents with HeFH should be screened after age 2 & I & $\mathrm{C}$ \\
\hline $\begin{array}{l}\text { Diagnosis of HeFH in children of HeFH parents is highly suspected by a LDL-C levels above } \\
3.5 \mathrm{mmol} / \mathrm{L}(>135 \mathrm{mg} / \mathrm{dL})\end{array}$ & I & $\mathrm{C}$ \\
\hline Diagnosis of FH in children of HeFH parents should be confirmed by DNA testing & I & $\mathrm{C}$ \\
\hline $\begin{array}{l}\text { HeFH young adults (after age } 18 \text { ) should receive statin therapy and their LDL-C levels reduced } \\
\text { below the common adult target }(<2.5 \mathrm{mmol} / \mathrm{L} \text { or } 100 \mathrm{mg} / \mathrm{dL} \text { ) }\end{array}$ & I & C \\
\hline $\begin{array}{l}\text { HeFH children younger than } 18 \text { years should receive statin from the age } 10 \text { years, in certain } \\
\text { conditions (see Table } 3 \text { ) }\end{array}$ & II a & $\mathrm{C}$ \\
\hline $\begin{array}{l}\text { In HeFH children, LDL-C should be reduced by } 30 \% \text { between age } 10 \text { and } 14 \text { years and below } \\
3.4 \mathrm{mmol} / \mathrm{L}(<130 \mathrm{mg} / \mathrm{dL}) \text { after } 14 \text { years }\end{array}$ & II a & $\mathrm{C}$ \\
\hline Children with HeFH need to be treated as early as possible & I & $\mathrm{C}$ \\
\hline
\end{tabular}

that larger LDL-C reductions produce larger reductions in vascular disease risk [42]. For children above 10 years and below 14 years, we only recommend that a reduction in LDL-C of $30 \%$ be achieved. After 14 years of age, reaching a specific target: below $3.4 \mathrm{mmol} / \mathrm{L}$ $(130 \mathrm{mg} / \mathrm{dL})$ becomes more important. After 18 years of age, the target could even be lowered to $2.5 \mathrm{mmol} / \mathrm{L}(100 \mathrm{mg} / \mathrm{dL})$, depending on the presence of other risk factors, as discussed by Civeira [15]. For each patient, before taking a decision about the target LDL-C and starting lifelong treatment, it is highly desirable to refer the patient to a centre specialised in the management of $\mathrm{HeFH}$.

\section{Other matters}

\subsection{Complementary examinations}

It is not recommended to perform carotid echography, cardiac exploration or ankle brachial index in routine practice. Outside of clinical trials, these examinations have not shown to have clear additional value for HeFH diagnosis, treatment decisions and prognostic information or for evaluating the effect of drugs on an individual subject. For example, in one study in HeFH children, the carotid IMT progressed on average at the rate of $0.005 \mathrm{~mm}$ per year [13], an increase that cannot be detected on an individual basis.

\subsection{Contraception}

Recommendations about contraception in most guidelines on $\mathrm{HeFH}$, and even in general guidelines on cardiovascular prevention focusing on women [50], are often absent, except in the latest UK NICE guidelines [19]. Because of the increased risk of myocardial infarction, stroke and peripheral artery disease [51] associated with oral contraception, it is advised to prescribe a statin as soon as girls are prescribed contraception. This applies to any form of contraceptive, including vaginal rings, as these are also known to increase ApoB, triglycerides and LDL-C [52]. Because statin teratogenicity remains controversial [53], it is advisable to prescribe contraception in female teenagers who are receiving statins and conversely to prescribe statins in those who are receiving oral contraception. It is important to prescribe a contraceptive formulation that increases LDL-C levels to the least extent and to carefully monitor LDL-C levels during oral contraceptive use. Young women treated with statins should also be warned to stop statin therapy before (planned) conception or as soon as pregnancy is diagnosed.

\subsection{Physical activity}

There is no contraindication for physical activity in children with $\mathrm{HeFH}$. As in any other high risk condition for CVD, increased physical activity remains of great importance for the many benefits it can induce. It is however important to understand that physical activity does not have a significant effect on lipids and cannot be used as a substitute for drug therapy when LDL-C lowering is required.

\subsection{Other drugs that influence cholesterol levels}

Amongst the drugs increasing LDL-C levels, and regularly prescribed during this period of life, are the isotretinoins used for the treatment of acne. These treatments increase thromboembolic risk as well as cardiovascular risk. Therefore they should be avoided in untreated HeFH children. However, if the LDL-C is lowered to within the normal range by an optimal treatment, it is likely that such a risk would equal that of children without HeFH. As in any other child, follow up of lipid levels is recommended.

\section{Homozygous familial hypercholesterolemia}

These cases are extremely rare $(1 / 1,000,000)$, but it is important to detect them at birth. The diagnosed cases bear characteristic skin abnormalities: planar or tuberous cutaneous xanthomas. These are marks or small yellowish elevations, present since birth, which may be found anywhere on the skin but mostly in the intercommissural spaces of the hands and the extension faces of the joints (elbows and knees). The other extra-vascular deposits of cholesterol (corneal arcus, xanthelasmas and tendon xanthomas) generally appear later, rarely before the age of 8 or 10 years. Biologically, there is an increase in TC to over $16 \mathrm{mmol} / \mathrm{L}(600 \mathrm{mg} / \mathrm{dL})$ before the age of 10 years, and of LDL-C to more than $13 \mathrm{mmol} / \mathrm{L}$ $(500 \mathrm{mg} / \mathrm{dL}$ ) with normal triglycerides (often with reductions in HDL-C). The atherogenic risk in these children is very high, with cardiovascular complications presenting at a very early age (usually aortic valve stenosis), sometimes under the age of 10 years. Life expectancy, in the absence of effective treatment, does not exceed 20 years, so it is important to look out for these cases in all couples in which both parents are carriers of HeFH (the risk for the offspring being 1/4). Besides standard treatments (statins from the youngest age), these patients can benefit from the addition of ezetimibe and/or bile acid chelators, as well as exceptional therapeutic options, such as LDL apheresis [54], liver transplant, liver cell grafts $[55,56]$ or gene or antisense RNA therapy [57].

\section{Conclusions}

The aim of this consensus statement is to achieve more consistent management in the identification and treatment of children with $\mathrm{HeFH}$ in Belgium and Europe. Although we are confident that these recommendations are easily acceptable to most practitioners, we must acknowledge that there is little clear evidence to support some of the recommendations (grading in Table 4). Therefore, we advocate future collaborative studies to clarify the benefits of different treatment strategies with regards to age at initiation of therapy, specific indications and statin dosage. 
In many countries, the critical problem of reimbursement of lipid-reducing drugs in children is still a burning issue. For example, in Belgium, it has up to now, been limited to those with TC above $8 \mathrm{mmol} / \mathrm{L}(300 \mathrm{mg} / \mathrm{dL}$ ) and a positive genetic test or a positive cardiovascular history in a first degree relative.

Of course, besides recommendations, the overall management process in these children also necessitates specific skills and strategies for facilitating change and adherence to medical treatment by the provision of information, including communication of the diagnosis. Regarding this issue, we refer to the excellent book of Edwards and Davis [58]. It is of course imperative to obtain the acceptance, understanding and advice of the parents in order to facilitate compliance of the child to the prescribed treatment, especially regarding drug treatment. That is why, in our recommendation, one of the first steps in the management of FH children is also to ensure the confirmation of the diagnosis and the treatment of the FH parent (see Section 4.2.1).

\section{Acknowledgments}

We thank Steve Humphries (Cardiovascular Medicine, UCL Division of Medicine, University College London) and Albert Wiegman (Departments of Pediatrics and Vascular Medicine, Academic Medical Centre, University of Amsterdam) for their expertise in reading the present guidelines and in providing constructive advice. We also thank Benoit Boland (Institut de recherche santé et société, Brussels) for his suggestions regarding the use of the AGREE protocol and as well as Nathalie Hanet Hélène Bauwens (anthropologist) for useful advices in conducting the team management.

The authors would also like to thank Michelle Derbyshire of MD Writing Services for providing assistance with the preparation of this manuscript. Olivier Descamps who leads the team during this 3-years work dedicated it to his wife, Caroline Daumerie, for her patience and wholehearted support.

\section{References}

[1] Goldstein JL, Hobbs HH, Brown MS. Familial hypercholesterolemia. In: Scriver CR, Sly WS, Childs B, et al, editors. The metabolic and molecular bases of inherited disease. 8th ed. New York, NY: McGraw-Hill Companies Inc.; 2001. p. 2863-913.

[2] Tsimikas S, Witztum JL. Shifting the diagnosis and treatment of atherosclerosis to children and young adults: a new paradigm for the 21st century. J Am Coll Cardiol 2002;40:2122-4.

[3] Iughetti L, Predieri B, Balli F, Calandra S. Rational approach to the treatment for heterozygous familial hypercholesterolemia in childhood and adolescence: a review. J Endocrinol Invest 2007;30:700-19.

[4] Sorensen KE, Celermajer DS, Georgakopoulos D, et al. Impairment of endothelium-dependent dilation is an early event in children with familial hypercholesterolemia and is related to the lipoprotein(a) level. J Clin Invest 1994;93:50-5.

[5] Lavrencic A, Kosmina B, Keber I, Videcnik V, Keber D. Carotid intimamedia thickness in young patients with familial hypercholesterolemia. Heart 1996;76:321-5

[6] Tonstad S, Joakimsen O, Stensland-Bugge E, et al. Risk factors related to carotid intima-media thickness and plaque in children with familial hypercholesterolemia and control subjects. Arterioscler Thromb Vasc Biol 1996;16:984-91.

[7] Raitakari OT, Juonala M, Kähönen $M$, et al. Cardiovascular risk factors in childhood and carotid artery intima-media thickness in adulthood: the Cardiovascular Risk in Young Finns Study. JAMA 2003;290:2277-83.

[8] Li S, Chen W, Srinivasan SR, et al. Childhood cardiovascular risk factors and carotid vascular changes in adulthood: the Bogalusa Heart Study. JAMA 2003;290:2271-6.

[9] Davis PH, Dawson JD, Riley WA, Lauer RM. Carotid intimal-medial thickness is related to cardiovascular risk factors measured from childhood through middle age: The Muscatine Study. Circulation 2001;104:2815-9.

[10] Rodenburg J, Vissers MN, Wiegman A, Trip MD, Bakker HD, Kastelein JJ. Familial hypercholesterolemia in children. Curr Opin Lipidol 2004;15:405-11.

[11] Avis HJ, Vissers MN, Stein EA, et al. A systematic review and meta-analysis of statin therapy in children with familial hypercholesterolemia. Arterioscler Thromb Vasc Biol 2007;27:1803-10.

[12] de Jongh S, Lilien MR, op't Roodt J, et al. Early statin therapy restores endothelial function in children with familial hypercholesterolemia. J Am Coll Cardiol 2002;40:2117-21.
[13] Wiegman A, Hutten BA, de Groot E, et al. Efficacy and safety of statin therapy in children with familial hypercholesterolemia: a randomized controlled trial. JAMA 2004;292:331-7.

[14] Koeijvoets KC, Rodenburg J, Hutten BA, et al. Low-density lipoprotein receptor genotype and response to pravastatin in children with familial hypercholesterolemia: substudy of an intima-media thickness trial. Circulation 2005;112:3168-73.

[15] Civeira F. International panel on management of familial hypercholesterolemia, guidelines for the diagnosis and management of heterozygous familial hypercholesterolemia. Atherosclerosis 2004;173:55-68.

[16] Descamps OS, Gilbeau JB, Luwaert R, Heller F. Impact of genetic defects on coronary atherosclerosis in patients suspected of familial hypercholesterolemia. Eur J Clin Invest 2003;33:1-9.

[17] Kwiterovich PO. Recognition and management of dyslipidemia in children and adolescents. J Clin Endocrinol Metab 2008;93:4200-9.

[18] McCrindle BW, Urbina EM, Dennison BA, et al. Drug therapy of highrisk lipid abnormalities in children and adolescents: a scientific statement from the American Heart Association Atherosclerosis, Hypertension, and Obesity in Youth Committee, Council of Cardiovascular Disease in the Young, with the Council on Cardiovascular Nursing. Circulation 2007;115: 1948-67.

[19] Wierzbicki AS, Humphries SE, Minhas R, Guideline Development Group. Familial hypercholesterolaemia: summary of NICE guidance. BMJ 2008;337:a1095, doi:10.1136/bmj.a1095 [complete guideline in website (http://www.nice.org.uk/nicemedia/pdf/CG071NICEGuideline.pdf)].

[20] van der Graaf A, Kastelein JJ, Wiegman A. Heterozygous familial hypercholesterolaemia in childhood: cardiovascular risk prevention. J Inherit Metab Dis 2009;32:699-705.

[21] The AGREE Collaboration. AGREE Instrument, www.agreecollaboration.org.

[22] Zimmet P, Alberti G, Kaufman F, et al. International diabetes federation task force on epidemiology and prevention of diabetes. The metabolic syndrome in children and adolescents. Lancet 2007;369(9579):2059-61.

[23] Daniels SR, Greer FR, Committee on Nutrition. Lipid screening and cardiovascular health in childhood. Pediatrics 2008;122:198-208.

[24] Maahs DM, Wadwa RP, Bishop F, et al. Dyslipidemia in youth with diabetes: to treat or not to treat? J Pediatr 2008;153:458-65.

[25] Descamps OS, Bruniau M, Guilmot PF, Tonglet R, Heller FR. Lipoprotein concentrations in newborns are associated with allelic variations in their mothers. Atherosclerosis 2004;172:287-98.

[26] US Preventive Services Task Force. Screening for lipid disorders in children: US preventive task force recommendation statement. Pediatrics 2007; 120:e215-9.

[27] Hakanen M, Lagström H, Kaitosaari T, et al. Development of overweight in an atherosclerosis prevention trial starting in early childhood. The STRIP study. Int J Obes 2006;30:618-26.

[28] Friedman LA, Morrison JA, Daniels SR, McCarthy WF, Sprecher DL. Sensitivity and specificity of pediatric lipid determinations for adult lipid status: findings from the Princeton Lipid Research Clinics Prevalence Program Follow-up Study. Pediatrics 2006;118:165-72.

[29] Wiegman A, Rodenburg J, de Jongh S, et al. Family history and cardiovascular risk in familial hypercholesterolemia: data in more than 1000 children. Circulation 2003;107:1473-8.

[30] Benlian P, Turquet A, Carrat F, et al. Diagnosis scoring for clinical identification of children with heterozygous familial hypercholesterolemia. J Pediatr Gastroenterol Nutr 2009;48:456-63.

[31] Obarzanek E, Kimm SY, Barton BA, et al. Long-term safety and efficacy of a cholesterol-lowering diet in children with elevated low-density lipoprotein cholesterol: seven-year results of the Dietary Intervention Study in Children (DISC). Pediatrics 2001;107:256-64.

[32] Poustie VJ, Rutherford P. Dietary treatment for familial hypercholesterolemia. Cochrane Database Syst Rev 2001;2:CD001918.

[33] Sánchez-Bayle M, Soriano-Guillén L. Influence of dietary intervention on growth in children with hypercholesterolemia. Acta Paediatr 2003;92: 1043-6.

[34] Jakulj L, Vissers MN, Rodenburg J, et al. Plant stanols do not restore endothelial function in pre-pubertal children with familial hypercholesterolemia despite reduction of low-density lipoprotein cholesterol levels. J Pediatr 2006;148:495-500.

[35] Ketomaki A, Gylling H, Miettinen TA. Effects of plant stanol and sterol esters on serum phytosterols in a family with familial hypercholesterolemia including a homozygous subject. J Lab Clin Med 2004;143:255-62.

[36] Amundsen AL, Ntanios F, Put N, Ose L. Long-term compliance and changes in plasma lipids, plant sterols and carotenoids in children and parents with FH consuming plant sterol ester-enriched spread. Eur J Clin Nutr 2004;58:1612-20.

[37] Hooper L, Thompson RL, Harrison RA, et al. Risks and benefits of omega 3 fats for mortality, cardiovascular disease, and cancer: systematic review. BM] 2006;332:752-60.

[38] Engler MM, Engler MB, Malloy MJ, et al. Effect of docosahexaenoic acid on lipoprotein subclasses in hyperlipidemic children (the EARLY study). Am J Cardiol 2005;95:869-71.

[39] Zhan S, Ho SC. Meta-analysis of the effects of soy protein containing isoflavones on the lipid profile. Am J Clin Nutrition 2005;81:397-408.

[40] Weghuber D, Widhalm K. Effect of 3-month treatment of children and adolescents with familial and polygenic hypercholesterolaemia with a soyasubstituted diet. Br J Nutr 2008;99:281-6. 
[41] Martinez J, Lewi JE. An unusual case of gynecomastia associated with soy product consumption. Endocr Pract 2008;14:415-8.

[42] Baigent C, Keech A, Kearney PM, et al. Efficacy and safety of cholesterollowering treatment: prospective meta-analysis of data from 90,056 participants in 14 randomised trials of statins. Lancet 2005;366(9493): 1267-78.

[43] Donaghue KC, Chiarelli F, Trotta D, Allgrove J, Dahl-Jorgensen K. ISPAD Clinical Practice Consensus Guidelines 2009 Compendium. Microvascular and macrovascular complications associated with diabetes in children and adolescents. Pediatr Diabetes 2009;10(Suppl. 12):195-203.

[44] Arambepola C, Farmer AJ, Perera R, Neil HAW. Statin treatment for children and adolescents with heterozygous familial hypercholesterolaemia: a systematic review and meta-analysis. Atherosclerosis 2006;195:339-47.

[45] Wheeler KA, West RJ, Lloyd JK, Barley J. Double blind trial of bezafibrate in familial hypercholesterolaemia. Arch Dis Child 1985;60:34-7.

[46] Lioudaki E, Ganotakis ES, Mikhailidis DP. Ezetimibe, more than a low density lipoprotein cholesterol lowering drug? An update after 4 years. Curr Vasc Pharmacol 2011;9:62-86.

[47] Clauss S, Wai KM, Kavey RE, Kuehl K. Ezetimibe treatment of pediatric patients with hypercholesterolemia. J Pediatr 2009;154:869-72.

[48] Groot PH, Dijkhuis-Stoffelsma R, Grose WF, Ambagtsheer JJ, Fernandes J. The effects of colestipol hydrochloride on serum lipoprotein lipid and apolipoprotein B and A-I concentrations in children heterozygous for familial hypercholesterolemia. Acta Paediatr Scand 1983;72: $81-5$.
[49] Stein EA, Marais AD, Szamosi T, et al. Colesevelam hydrochloride: efficacy and safety in pediatric subjects with heterozygous familial hypercholesterolemia. J Pediatr 2010;156:231-6.

[50] Mosca L, Banka CL, Benjamin EJ, et al. Evidence-based guidelines for cardiovascular disease prevention in women: 2007 Update. Circulation 2007;115:1481-501.

[51] Rosendaal FR, Van Hylckama Vlieg A, Tanis BC, Helmerhorst FM. Estrogens, progestogens and thrombosis. J Thromb Haemost 2003;1:1371-80.

[52] Tuppurainen M, Klimscheffskij R, Venhola M, Dieben TO. The combined contraceptive vaginal ring (nuvaring) and lipid metabolism: a comparative study. Contraception 2004;69:389-94.

[53] Pollack PS, Shields KE, Burnett DM, et al. Pregnancy outcomes after materna exposure to simvastatin and lovastatin. Birth Defects Res A Clin Mol Terato 2005;73:888-96.

[54] Borberg H. 26 years of LDL-apheresis: a review of experience. Transfus Apher Sci 2009;41:49-59.

[55] Sokal EM, Ulla L, Harvengt C, Otte JB. Liver transplantation for familial hypercholesterolemia before the onset of cardiovascular complications. Transplantation 1993;55:432-3.

[56] Smets F, Najimi M, Sokal EM. Cell transplantation in the treatment of live diseases. Pediatr Transplant 2008;12:6-13.

[57] Akdim F, Stroes ES, Kastelein JJ. Antisense apolipoprotein B therapy: where do we stand? Curr Opin Lipidol 2007;18:397-400.

[58] Edwards M, Davis H. Counselling Children with Chronic Medical Conditions. Wiley-Blackwell; 1997 [Communication and Counselling in Health Care]. 